\title{
Comparative Language Learning Beliefs: Why Aptitude Matters
}

\author{
Laura V. Fielden Burns ${ }^{1 *} \&$ Mercedes Rico García ${ }^{2}$ \\ ${ }^{1}$ Department of Didactics en Social Sciences, Language and Literature, University of Extremadura, \\ Cáceres, Spain \\ ${ }^{2}$ Department of English Philology, University of Extremadura, Mérida Spain \\ * Laura V. Fielden Burns, E-mail: lvfielden@unex.es
}

Received: May 31, 2017

Accepted: June 26, 2017

Online Published: July 25, 2017

doi:10.22158/sll.v1n2p129

URL: http://dx.doi.org/10.22158/sll.v1n2p129

\begin{abstract}
Language Learning Beliefs (LLB) are an important area for foreign and second language learning research that has grown considerably over the last decade, and which spans multi-disciplinary fields across education, linguistics and psychology (Martínez Agudo, 2014). These beliefs have become more important as they affect motivation and perhaps even language learning strategies (Zare-ee, 2010), though more research must be done in the latter area (Martínez Agudo, 2014). One understudied branch of $L L B$ is that of language aptitude. Beliefs concerning language aptitude are not new, given that they appeared as a staple area of Horwitz's seminal research for the BALLI questionnaire (Beliefs About Language Learning Inventory) (1987). However, beliefs on language aptitude need to be revisited given the multiple studies in social psychology on how beliefs affect learning when considering a given quality as innate or learned (Dweck, 2014). These studies show how believing intelligence to be fixed or incremental has a variety of consequences for learners that are fundamental for their long-term success in the classroom. Our aim in this paper is to merge these pertinent concepts to the foreign language classroom, in particular because the belief that intelligence is fixed or incremental mirrors the long-standing debate over language aptitude as innate or learned.
\end{abstract}

\section{Keywords}

Language Learning Beliefs, aptitude, English, Portuguese

\section{Background}

\subsection{Language Learning Beliefs}

Studies led by Dweck and other scholars, though not focused specifically on language learners, have over the last 40 years shown the effect that beliefs about learning and intelligence have had on students' academic performance and goals (Dweck, 2014, 2006, 2000), as well as their anxiety levels, modes of self-talk when working through a challenge, and self-confidence (2000). They have demonstrated, for 
example, that when students favor an incremental (malleable) over an entity (fixed) theory of intelligence, they are more likely to report enjoying learning tasks over tasks that merely demonstrate their skills as a performance (Dweck, 1989, p. 103) and are more resilient in the face of challenges or obstacles (Licht \& Dweck, 1984; Diener \& Dweck, 1978). The other side of this coin is that when students favor an entity, or fixed, theory of intelligence, they tend to attribute their failures to lack of ability rather than effort, often blaming their intelligence, and report seeing others as better than they are (even when no difference exists in actual ability or performance according to prior testing) (Licht \& Dweck, 1984). They also tend to abandon active strategizing more quickly (Diener \& Dweck, 1978, 1980) and avoid obstacles and challenges (Dweck, 1975).

Horwitz, a pioneer in language learning beliefs research (1988) defined these beliefs as students' “opinions on a variety of issues and controversies related to language learning” (p. 284). Scholars have examined SLA beliefs in language learning of a diverse range, including those about language teachers' roles (Nikitina \& Furuoka, 2007), the impact of methodology on beliefs (Kunt, 2010), beliefs about certain skills like speaking (Sioson, 2011) or grammar and vocabulary (Peacock, 1999), readiness and self-competency (Polat, 2010), self-efficacy (Magogwe \& Oliver, 2007), and autonomy (Holec, 1987). Barcelos, in her first review of research on SLA beliefs (2003), further defined these, calling them "opinions or ideas about the task of learning a foreign or second language, these being socially constructed" (p. 231). This social construction was emphasized further a decade later, when the same scholar reviewed changes in SLA belief research (2011) and separated language learning belief research into two chronological phases: contextual, where scholars have focused on recognizing and describing beliefs within their context, and socio-cultural, which looks at how beliefs develop, are negotiated, and interact among and as a result of socio-cultural forces.

In a more extensive review, Wesely (2012) organized this research into three principal branches: studies related to traits/characteristics; studies related to the learning environment, and studies that look at these two concepts in terms of the interaction between the learner and her or his environment. The principal differences here are source: where the attitudes, perceptions, and beliefs come from (students themselves or their environment), and permeability: to what degree these can be altered. These two qualities have been key to the great majority of SLA belief/perception/attitude research, as well as the branches that depend on it, like motivation.

\subsection{Beliefs About Language Learning Aptitude}

The great majority of studies focusing on SLA beliefs have some basis in Horwitz (1988) and her BALLI questionnaire, where one of the most interesting areas, which has been maintained in the vast majority of BALLI-based instruments (Saku \& Gaies, 1999; Nikitina \& Furoka, 2007; Reiger, 2009 to name a few), is that of language learning "aptitude". The struggle to define this term represents a fundamental debate in language acquisition, in particular its innate or learned quality. Scholars in this debate often focus on aptitude measurement, beginning for many with the work of Carroll and Sapon, the authors of the Modern Language Aptitude Test (MLAT) (1959). The MLAT, a psychometric test, is still one of the Published by SCHOLINK INC. 
most well-known and widely used tests for assessing language aptitude. In general the MLAT seems to measure a fixed construct, as a manual promoting its commercial use, downloaded from its website in May of 2017, describes aptitude in quite static terms:

The MLAT measures aptitude, not achievement or proficiency. Therefore it is not possible to prepare for the test. A high score on the MLAT indicates that an individual will likely do well in language training. Previous success at learning a foreign language may also contribute to the probability of learning another language but it will not appreciably change one's score on the MLAT (Stansfield, n.d., p. 5).

Furthermore (emphasis added), because aptitude is an inherent trait in human beings, the degree of aptitude in major population groups does not change appreciably over time.

Language aptitude as measured by the MLAT is mostly viewed as a stable trait, one not readily subject to change or improvement through courses or experience. Thus, when properly administered, the MLAT yields a score that theoretically is good for life, although certain circumstance might lead one to consider retesting (Stansfield, n.d., p. 4).

Sáfár and Kormos (2008) call this focus on a static, innate trait one of the principal problems with the MLAT. They in fact show, in a study with teenagers learning English, that language aptitude was affected by language learning experience, concluding that "aptitude is a skill, not an underlying ability" (p. 26).

Wen (2011) reviewed the history of language aptitude and noted that it has gone from being understood as a "stable and unitary fixed trait" to being seen as "dynamic and multiple sets of malleable abilities that interact” (p. 234). This is so because numerous scholars have begun to question the unchanging nature of aptitude. Sáfar and Kormos (2008) note that: “... previous research does not provide conclusive evidence either for or against stability in language aptitude. Despite the lack of evidence, the assumption of stability is rarely called into question” (p. 6). Cochran, McCallum, and Bell (2010), when comparing aptitude, attribution, and attitude for foreign language success in 648 university students, concluded that attitude, not aptitude, was the primary predictor for success. Ranta (2002) looked specifically at how the course environment was important to the role of aptitude, discussing how analytic language abilities like those tested on the MLAT were not important to communicative types of language courses. Finally, some researchers have postulated that working memory, rather than aptitude, is more important to language success (Miyake \& Friedman, 1998, as cited in Sáfár \& Kormos, 2008; Wen, 2011), a theory that Sáfár and Kormos successfully put to the test (2008).

What is more, recent studies, such as that of Suárez and Muñoz (2011), demonstrate that areas of students' MLAT scores have indeed improved following language study. In this study, MLAT scores increased as 325 bilingual children in Cataluña moved up through school levels, indicating that aptitude may not be as static as previously thought. Even given the concerns of these and many other scholars who have questioned the importance of aptitude as it is established therein, the MLAT is still the most utilized language aptitude test today, and in many ways has come to be the last word on its definition. This may be rather circular, as Dörnyei (2005) indicates: "the tacit understanding in the L2 research community Published by SCHOLINK INC. 
has been that language aptitude is what language aptitude tests measure” (p. 35).

Despite the synergies in these areas, where SLA research is calling to revisit concepts of language aptitude, and in particular concepts of aptitude as static, and where studies in education and social psychology are revealing the negative consequences of students' beliefs that intelligence is fixed, they have not yet been married in current SLA research. What is more, such beliefs may be related to beliefs about specific languages. Horwitz and others have referenced how students' beliefs differ when we compare, for example, students studying English in Turkey with EFL students in France, or American students studying Spanish versus those taking Japanese. Horwitz (1999) and Mori (1999) in fact investigate beliefs about a given language's intrinsic difficulty as a differentiating item for the language of study of the BALLI takers. However, few studies have examined the same students' beliefs about different languages. Diab (2006) compared beliefs of the same Lebanese university students ( $\mathrm{N}=284)$ about French and English, both of these as a foreign language, and found that students viewed French as easier than English. In a recent study by Meshkat and Saeb (2014) on 584 high school students in Iran and their beliefs concerning English and Arabic as foreign languages, no statistical difference was found between the languages. Neither of these studies commented on beliefs about aptitude in the different languages.

Comparing student beliefs about different languages is an interesting research line for several reasons. To begin with, it differentiates how we understand language learning beliefs by offering a comparative context for perceptions on different languages, and thus, to some extent given their interrelatedness (Citron, 1995), culture. Secondly, it highlights the languages under study, so that we might consider student responses to be more concretely about that language, and not about language in general. The study at hand tries to shed some light on how students' beliefs about aptitude differ when considering learning two different languages.

\section{Study: Fixed and Incremental Visions of Learning English and Portuguese in Extremadura,} Spain

This study examined beliefs about language learning aptitude through a fixed/incremental theoretical framework (Dweck, 2000). An interesting feature of this study was that it examined student beliefs comparatively with English and Portuguese. Looking at student beliefs comparatively makes sense, given that it's feasible to see one languages as closer or further from one's own, culturally, or linguistically, and that such a perspective may affect beliefs about learning it.

English was chosen given its status as a lingua franca, in particular in hospitality studies, and because it was the course all students had in common in the group. Portuguese was chosen to be compared with English as a foreign language since was also a language many students in the group were taking at the same school, and given its similarity to the native language, Spanish. Importantly, Portuguese is also key to the geographic area of the students, since Portugal and Extremadura share a border and are culturally very familiar to one another. This presented a unique opportunity to examine differences in language Published by SCHOLINK INC. 
learning beliefs among the students when they compared a language quite similar to their own, and very familiar to them culturally, with another language being learnt, English. Differences in beliefs then would be attributed to how they see English, and not simply how students view languages in general (Mercer, 2011).

Research question:

Do student beliefs on aptitude for learning English differ from their beliefs about learning Portuguese when examined in a fixed/incremental framework?

\subsection{Methodology}

\subsubsection{Participants}

The participants were adults taking continuing education and professional certification courses in a public hospitality school in Extremadura, Spain. The courses were two English for Restaurant Service (A1-A2 level) courses (90 hours), as well as English for Tourism (A2 level, 120 hours total) which makes them English for Occupational Purposes students. Some of the students were also taking Portuguese for Tourism (A2). There was a total of $51(\mathrm{~N}=51)$ participants in the sample group.

The students took part in the study voluntarily and were made up of a diverse range of ages and educational backgrounds. A little less than half of the group was university-educated $(\mathrm{N}=22)$, followed by high school studies (university prep) $(\mathrm{N}=14)$ and technical or vocational certificates $(\mathrm{N}=10)$. A wide variety of age groups were represented in the participant population, with a large group of 35 and under $(\mathrm{N}=33)$, but also with a wide band of persons between 36-40 years of age. There were more women $(\mathrm{N}=29)$ in the groups than men.

\subsubsection{Instruments and Materials}

The principal study instrument was a student opinion questionnaire designed for this purpose, and based on Dweck (2000, pp. 178-186). It was created by the authors for the purpose of this study and included areas pertinent to student beliefs (motivation, personal data, etc.) in language learning.

\subsubsection{Language Translation and Pilot Test}

The questionnaire was written in Spanish and reviewed in its final format by three experts in foreign language and two psychologists. Volunteer English students who were not from the hospitality school took the questionnaire using the "think-aloud" method to aid in item construction and coherence (Lewis, 1982). Finally, the questionnaire was first tested in a pilot group of 21 different students from the same courses the semester previous in the hospitality school.

\subsubsection{Response Format}

The response format was a semantic differential scale (Osgood, 1957), asking respondents to signal their answers by marking one spot on an unnumbered continuum. These scales are similar to Likert scales in that by adding up individual items one can reach a multi-item score. In this type of visual scale students can interpret the worded options at each extreme as leanings toward one side or another, with no exclusive response necessary, and a clear neutral response in the middle. The order was staggered so as to avoid social desirability bias which occurs when what is considered the positive side of the scale is

Published by SCHOLINK INC. 
consistently ordered the same. In the items below a more incremental stance (less static, fixed) is in bold for the purposes of this explanation, and would represent the higher end of the scale, a 7 numerically. The opposite side would be a 1 , the lowest point on the response scale.

\section{Aptitude for English/Portuguese is:}

Innate: $\bullet: \triangleright: \square: \triangleright: \square: \square: \square:$ Learned

Changeable : $\square: \square: \square: \square: \square: \square: \square:$ Not changeable

Talent : $:: \triangleright: \square: \square: \square: \square: \triangleright:$ Practice

Improvable: $\square: \square: \triangleright: \triangleright: \triangleright: \square: \square:$ Not improvable

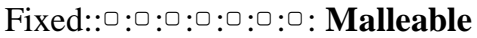

Not limited: $\triangleright: \square: \square: \triangleright: \triangleright: \triangleright: \triangleright:$ Limited

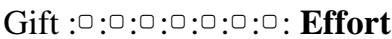

On the student questionnaire there were two separate blocks for English and Portuguese Aptitude, with the exact same items, but these are reduced here for space purposes.

\subsubsection{Test Reliability}

The Beliefs questionnaire was tested for reliability once the pilot phases had been finished. The ratio used for this purpose was Cronbach's alpha (Triola, 2006), indicating internal consistency of items. The calculation performed in this study show a variable value of 0.806 , which can be considered appropriate, since the majority of experts agree that the standard for test reliability begins at 0.6 (Malhotra, 2004). Finally, construct validity was obtained by allowing two experts in the field of psychology familiar with the constructs and the purpose to review the questionnaire and make comments and suggestions.

\subsubsection{Procedure and Administration}

Students were administered the Beliefs questionnaire approximately one week after courses began. These were administered in class, by their teacher, where students were told that their participation was voluntary.

\subsubsection{Statistical Analysis}

Statistical analysis was conducted using SPSS software, version 19, which is used to quantitatively describe the main features of a collection of data. Given that the variables of the questionnaires are measured here on numerical scale these are considered ordinal variables and so determine the kind of contrast that can be employed. The appropriate statistical method for this study is nonparametric, i.e., it does not depend on the population fitting any parameterized distributions.

\section{Results}

The research question posed in this study examined what students believe about English learning aptitude in terms of it having a more fixed or malleable nature. Following the research lines of Meshkat and Saeb (2014), we asked if students' opinions differed where different languages were concerned, so 
aptitude beliefs about Portuguese and English were investigated to see if beliefs changed in any way, both languages being studied at the hospitality school at that time. If students' beliefs altered when comparing the languages this would further indicate that the opinions they expressed on English aptitude were specific to English language learning, and might shed new light on language learning beliefs in general.

Thus, comparing the results obtained from respondents' beliefs about aptitude for Portuguese and English on the questionnaire administered to students, the sum of the variables, named here "Total", was calculated for each language, which is the average of the scores of all the items. The graph below for this set of variables (Figure 1) gives a first approximation on the beliefs about aptitude in both languages, where English is blue and Portuguese is red:

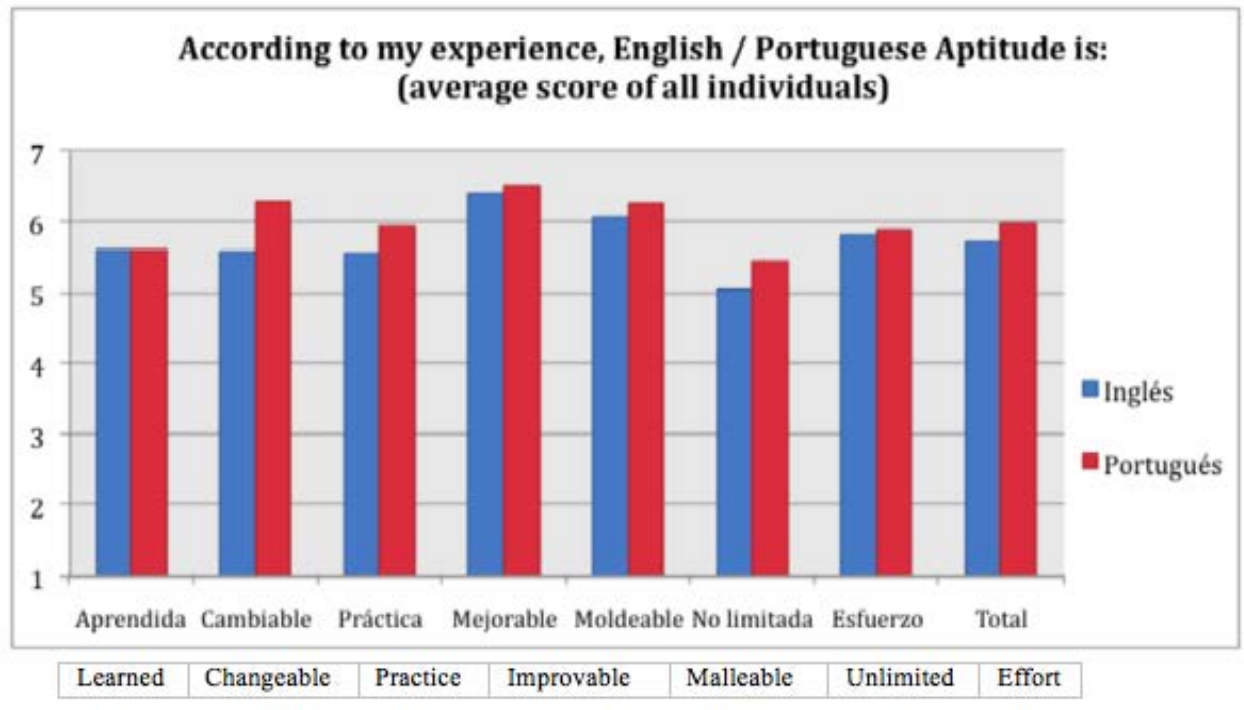

Figure 1. English and Portuguese Aptitude Beliefs Compared

Given that the scale (left-hand side) is from one to seven, seven being the most incremental, all variables had quite high scores, over five, indicating that the group considered aptitude for both languages to be more incremental than fixed. Analyzing the results by language shows how Portuguese had higher scores on six of the seven variables (Learned, Changeable, Practice, Improvable, Malleable, Unlimited, and Effort) analyzed (and a tie in the seventh), which seems to point toward English aptitude as more fixed when compared with Portuguese. Interestingly, the variables with the highest and lowest scores reveal some differences: individuals seemed to strongly believe that this aptitude can be improved (“mejorable"), but when confronted with aptitude as "unlimited”, scores were more moderate. This perhaps points toward understanding improvement as feasible, but ultimately capped at some level.

To determine whether the observed differences were really significant, a hypothesis testing was conducted using the Wilcoxon Test (signed rank test for paired samples). This test can take the magnitude of differences into account since it uses ranks, which allow its conclusions to better reflect the Published by SCHOLINK INC. 
data's nature (Triola, 2005). The null hypothesis is that the beliefs on both languages are equal, where the alternative indicates that opinions about Portuguese rank lower, or as more fixed. The contrast indicates that all variables show differences between the two languages with a significance level of 95\%. Therefore, it can be concluded that the respondent group considered English language aptitude to be more fixed than language aptitude for Portuguese. The Box-plot diagram, a graph of a data whose line extends from the minimum value to the maximum value and a box drawn at the first quartile, the median and the third quartile (Figure 2 below), shows the overall differences visually, with English on the left. In the diagram below, the scale numeration (left-hand side) begins at neutral four and moves up to the most incremental point of the scale, seven.

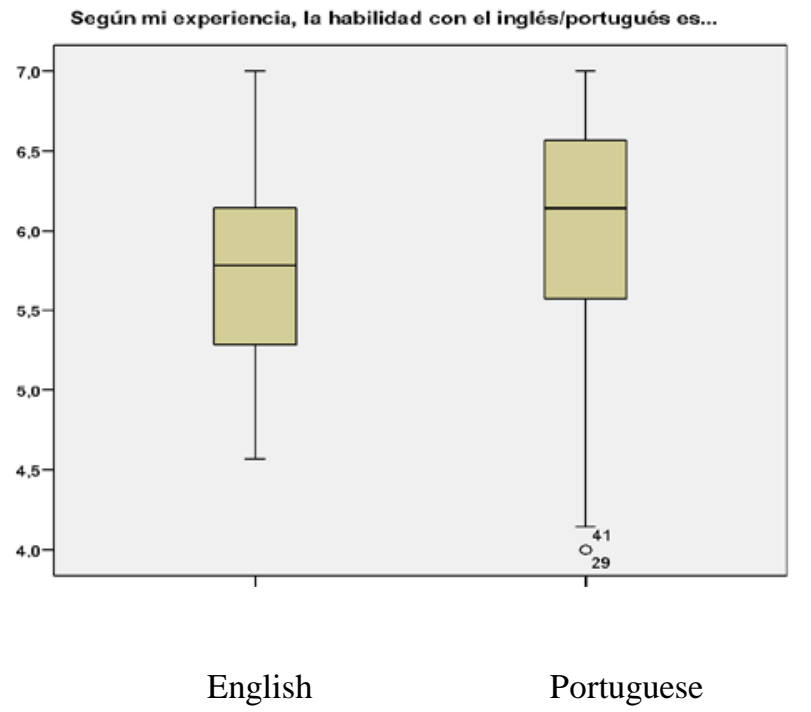

Figure 2. Box-Plot English and Portuguese Aptitude Totals Compared

In the box-plot above one can observe how the box on the right, students' opinions about Portuguese aptitude, is higher than the box on the left, which represents English aptitude. It hovers around 6.5 on the scale on the left. It is also longer, which indicates a greater variety of dispersion. The tendency of data to be scattered over a range, also known as spread or variation. Less dispersion means greater uniformity of responses, which is desirable in a data set. Here one sees then in the Portuguese block more variety of responses, whereas the box representing the opinions about English aptitude is smaller and more compact, meaning that students' opinions here were more similar to one another as they all fall in the same area. These results show that although students marked aptitude as generally incremental, they did differentiate between English and Portuguese aptitude.

Students in this group saw English language aptitude as generally incremental with a total block averages of 5.7 on a 7 point scale. However, when comparing English to a foreign language similar to their own, students significantly viewed Portuguese as even more incremental than English at 95\% with all variables being significantly higher for Portuguese than for English. This 95\% has a p-value of 0.021, Published by SCHOLINK INC. 
which helps determine the significance of results obtained, since a small p-value, typically less than or equal to 0.05 , indicates strong evidence against the null hypothesis (Triola, 2012).

\section{Discussion and Conclusions}

This paper examined language aptitude beliefs, asking whether EFL students see English and Portuguese language aptitude as something that is static and innate, or incremental and learned. This was important since the literature reviewed indicated that aptitude was an important area to consider in SLA beliefs as one of the more salient areas of Horwitz's and others' studies with the BALLI, though it was not one that had been focused on explicitly in the past, or from the perspective of a fixed/incremental framework. Students were asked about aptitude for English, the lingua franca for tourism and hospitality studies, and Portuguese, a language familiar to them given Extremadura's shared border with Portugal. Spanish is very close to Portuguese in the family of Latin languages, so here students may see it as more "like" their own language. More importantly, Portuguese is familiar to Extremadurans as a neighbor tongue that many experience and live on a personal scale, traveling frequently to Portugal, living or working close to the border, having family members in villages that were once Portuguese (Olivenza, for example), etc. Although students' views were largely incremental for English aptitude, they did statistically view English aptitude as more fixed than Portuguese both at the item and block levels. English was viewed as more fixed and innate, and perhaps as a result, less changeable. Perhaps in this sense, they saw English as less like their own, culturally or linguistically speaking. This may in part be influenced by the extrinsic pressure placed on Spaniards in general to learn English from a very young age, evident in the proliferation of CLIL or bilingual programs in English in most public schools. Student opinions were also more concentrated and may be considered more definitive.

This is an important distinction and indicates that student beliefs about aptitude are influenced by other beliefs about languages and culture, and how these are different, which Horwitz (1999) and Mori (1999) touched upon when looking at the intrinsic difficulty of a given language. If we compare our results with those of previous studies we find some differences. Horwitz and Mori (ibid) did not compare the same students' beliefs about different languages, which is a limitation in this sense. Horwitz's studies were carried out across a range of cultures, which seems to be related. Responses to the BALLI questionnaire differed greatly depending on the language under study and the culture of the students studying it, for example 66-85\% of American students studying Japanese believed in an innate language aptitude, while only 46-52\% of American students studying French, Spanish, and German did. Diab (2006) examined students' beliefs about French and English, where students statistically viewed French as easier than English, but Meshkat and Saeb (2014) found no difference in Iranian students' beliefs concerning Arabic and English. Clearly, beliefs about language aptitude vary depending on the language in question and the cultural perspective in which is it being asked.

Years of research in student beliefs have indicated that SLA beliefs are essential to students' language learning development, affecting motivation and even strategy use or test scores (Barcelos \& Kalaja, 2003,

Published by SCHOLINK INC. 
2011; Weseley, 2012). Parallel development in social psychology in the area of education pointed to the importance of student beliefs in a fundamental concept in learning: intelligence as given or developed, coined by Dweck $(2014,2000)$ as the fixed or incremental mindset. Marrying beliefs about language aptitude to a fixed/incremental framework and explicitly inquiring into the degree to which each of these is perceived to be innate or developed was a way to fill this gap. No previous study has looked at beliefs from this specific angle, or from within this population: adult students studying English in Spain.

The results indicate that this study adds significant dimension to what is already known about SLA beliefs which should be taken into account for future investigations, in particular:

1) The need to include a fixed/incremental framework, when examining aptitude and beliefs in SLA belief research.

Previous studies did not look closely at language aptitude beliefs in themselves, or consider this particular framework, incremental and fixed beliefs, as important to how we examine SLA beliefs about aptitude, in particular. This study shows that the fixed or incremental framework is indeed pertinent to students' second language acquisition beliefs about aptitude.

2) What students believe about aptitude for one language may not apply to another.

The BALLI studies looked at and compared different students of particular languages (students of Spanish versus students of Japanese, for example), and showed some very interesting results, but they did not often look at the same students' beliefs about aptitude for different languages. The present study shows that this is important, since students clearly differentiated in their beliefs about the fixedness of English and Portuguese, seeing the language that was less like their own, English, as significantly more static even when they rated English overall as incremental. However, this was not seen in other studies such as Meshkat and Saeb (2014), and merits further investigation. So, belief surveys should inquire into what students believe about different languages, in particular those deemed closer or more foreign to their own native tongues. It would be interesting to gain further insight into the motivation behind these beliefs, if related, in terms of their instrumentality or integrativeness, since motivation to learn one language in this case, Portuguese, may be related to personal reasons of proximity.

What is more, these results have pedagogical implications that should be considered. Related studies in intelligence beliefs (Dweck, 2000) showed that students' beliefs in intelligence as fixed or malleable affected their learning strategies and persistence. In this vein, students' beliefs that some languages can be learnt better through practice, while others need innate talent, could also feasibly affect how they approach learning these languages in the classroom, including their persistence in studying a determined language toward its mastery. This must be important for language teachers to consider, not simply for their practical application, in terms of keeping students in language study long enough to master it to some useful degree, but also in terms of the fact that instructors can have an influence on students' beliefs. If some beliefs are shown to be more detrimental to study strategies, for example, then instructors might consider actively working with students to change these in order to be more effective in their teaching. 


\section{References}

Barcelos, A. M. F., \& Kalaja, P. (2003). Exploring possibilities for future research on beliefs about SLA. In A. M. F. Barcelos, \& P. Kalaja (Eds.), Beliefs about SLA: New research approaches (pp. 231-238). Kluwer Academic Publishers.

Barcelos, A. M. F., \& Kalaja, P. (2011). Introduction to beliefs about SLA revisited. System, 39(3), 281-289. https://doi.org/10.1016/j.system.2011.07.001

Carroll, J. B., \& Sapon, S. M. (1959). Modern Language Aptitude Test (MLAT). San Antonio: Psychological Corporation.

Citron, J. L. (1995). Can cross-cultural understanding aid second language acquisition? Toward a theory of ethno-lingual relativity. Hispania, 78(1), 105-113. https://doi.org/10.2307/345230

Cochran, J. L., McCallum, R. S., \& Bell, S. M. (2010). Three A’s: How do attributions, attitudes, and aptitude contribute to foreign language learning? Foreign Language Annals, 43(4), 566-582. https://doi.org/10.1111/j.1944-9720.2010.01102.x

Diab, R. L. (2006). University students’ beliefs about learning English and French in Lebanon. English, 34, 80-96. https://doi.org/10.1016/j.system.2005.06.014

Diener, C., \& Dweck, C. S. (1978). An analysis of learned helplessness: Continuous changes in performance, strategy, and achievement cognitions following failure. Journal of Personality and Social Psychology, 36(5), 451-462. https://doi.org/10.1037/0022-3514.36.5.451

Diener, C., \& Dweck, C. S. (1980). An analysis of learned helplessness (II): The processing of success. Journal of Personality and Social Psychology, 39(5), 940-952. https://doi.org/10.1037/0022-3514.39.5.940

Dörnyei, Z. (2005). The psychology of the language learner: Individual differences in second language acquisition. Mahwah, New Jersey: Lawrence Erlbaum Associates.

Dweck, C. S. (1975). The role of expectations and attributions in the alleviation of learned helplessness. Journal of Personality and Social Psychology, 31(4), 674-685. https://doi.org/10.1037/h0077149

Dweck, C. S. (1989). Motivation. In A. Lesgold, \& R. Glaser (Eds.), Foundations for a psychology of education (Vol. 1, pp. 87-136). Hillsadale, NJ: Erlbaum.

Dweck, C. S. (2000). Self-theories: Their role in motivation, personality and development. Philadelphia, PA: Taylor \& Francis.

Dweck, C. S. (2006). Mindset: The new psychology of success. New York: Ballantine Books.

Dweck, C., Walton, G., \& Cohen, G. (2014). Academic tenacity: Mindsets and skills that promote long-term learning. Bill and Melinda Gates Foundation. Retrieved April 2017, from https://ed.stanford.edu/sites/default/files/manual/dweck-walton-cohen-2014.pdf

Holec, H. (1987). The learner as manager: Managing learning or managing to learn? In A. Wenden, \& J. Rubin (Eds.), Learner strategies in language learning (pp. 145-157). London: Prentice-Hall International.

Horwitz, E. K. (1988). The beliefs about language learning of beginning university foreign language Published by SCHOLINK INC. 
$\begin{array}{llll}\text { students. } & \text { Modern } & \text { Language }\end{array}$ https://doi.org/10.1111/j.1540-4781.1988.tb04190.x

Horwitz, E. K. (1999). Cultural and situational influences on foreign language learners' beliefs about language learning: A review of BALLI studies. System, 27, 557-576. https://doi.org/10.1016/S0346-251X(99)00050-0

Kunt, N. (2010). Impact of methodology courses on pre-service EFL teachers' beliefs. Career and Technical Education Research, 2, 3938-3944. https://doi.org/10.1016/j.sbspro.2010.03.620

Licht, B., \& Dweck, C. S. (1984). Determinants of academic achievement: The interaction of children's achievement orientations with skill area. Developmental Psychology, 20(4), 628-636. https://doi.org/10.1037/0012-1649.20.4.628

Magogwe, J. M., \& Oliver, R. (2007). The relationship between language learning strategies, proficiency, age and self-efficacy beliefs: A study of language learners in Botswana. System, 35(3), 338-352. https://doi.org/10.1016/j.system.2007.01.003

Malhotra, N. K. (2004). Marketing Research: An Applied Orientation (4th ed). Pearson Education, Inc: New Jersey.

Martínez Agudo, J. (2014). Analysing Spanish learners’ beliefs about EFL learning. Porta Linguarum, 22(June), 285-301. Retrieved from http://www.ugr.es/ portalin/articulos/PL_numero22/19 Juan de Dios.pdf

Mercer, S. (2011). Internal frames of reference in FL self-concept formation. In S. Mercer (Ed.), Towards an understanding of language learner self-concept (pp. 97-125). London: Educational Linguistics. https://doi.org/10.1007/978-90-481-9569-5_5

Meshkat, M., \& Saeb, F. (2014). High-school students' beliefs about learning English and Arabic. International Journal of Applied Linguistics \& English Literature, 3(3), 211-216. https://doi.org/10.7575/aiac.ijalel.v.3n.3p.211

Miyake, A., \& Friedman, N. (1998). Individual differences in second language proficiency: Working memory as language aptitude. In A. Healy, \& L. Bourne (Eds.), Foreign Language Psycholinguistic Studies on Training and Retention (pp. 339-364). Mahwah, NJ.

Mori, Y. (1999). Beliefs about language learning and their relationship to the ability to integrate information from word parts and context in interpreting novel Kanji words. The Modern Language Journal, 83(iv), 534-547. https://doi.org/10.1111/0026-7902.00039

Nikitina, L., \& Furuoka, F. (2007). Measuring metaphors: A factor analysis of students' conceptions of language teachers. Educational Research, 161-180.

Osgood, C. E., Suci, G., \& Tannenbaum, P. (1957). The measurement of meaning. Urbana, IL: University of Illinois Press.

Peacock, M. (1999). Beliefs about language learning and their relationship to Polat, N. (2010). A comparative analysis of pre-and in-service teacher beliefs about readiness and self-competency: Revisiting teacher education for ELLs. System, 38, 228-244. 
Ranta, L. (2002). The role of learners' analytic ability in the communicative classroom. In P. Robinson (Ed.), Individuals differences and instructed language learning (pp. 159-180). Amsterdam: John Benjamins. https://doi.org/10.1075/lltt.2.11ran

Rieger, B. (2009). Hungarian university students' beliefs about language learning: A questionnaire study. Working Papers in Language Pedagogy, 3, 97-113.

Sáfár, A., \& Kormos, J. (2008). Revisiting problems with foreign language aptitude. International Review of Applied Linguistics in Language Teaching, 46(2), 113-136. https://doi.org/10.1515/IRAL.2008.005

Sakui, K., \& Gaies, S. J. (1999). Investigating Japanese learners' beliefs about language learning. System, 27(4), 473-492. https://doi.org/10.1016/S0346-251X(99)00046-9

Siegle, D., Condon, E., \& Romey, E. A. (2007). Role of interest, ability, and effort in developing talent in college honors students. In Paper presented at the American Education Research Association Annual Meeting. Chicago, IL.

Sioson, I. C. (2011). Language learning strategies, beliefs, and anxiety in academic speaking tasks. Phillipine ESL Journal, 7(July), 3-27.

Suárez, M., \& Muñoz, C. (2011). Aptitude, age and cognitive development: The MLAT-E in Spanish and Catalan. EUROSLA Yearbook, 11(1), 5-29. https://doi.org/10.1075/eurosla.11.03sua

Triola, M. (2006). Elementary Statistics (10th ed). Pearson, Boston.

Wen, Z. (2011). Foreign language aptitude. ELT Journal, 66(2), 233-235. https://doi.org/10.1093/elt/ccr068

Wesely, P. M. (2012). Learner attitudes, perceptions, and beliefs in language learning. Foreign Language Annals, 45(Summer), 98-117. https://doi.org/10.1111/j.1944-9720.2012.01181.x

Zare-ee, A. (2010). Associations between university students' beliefs and their learning strategy use. Learning, 5, 882-886. https://doi.org/10.1016/j.sbspro.2010.07.203 